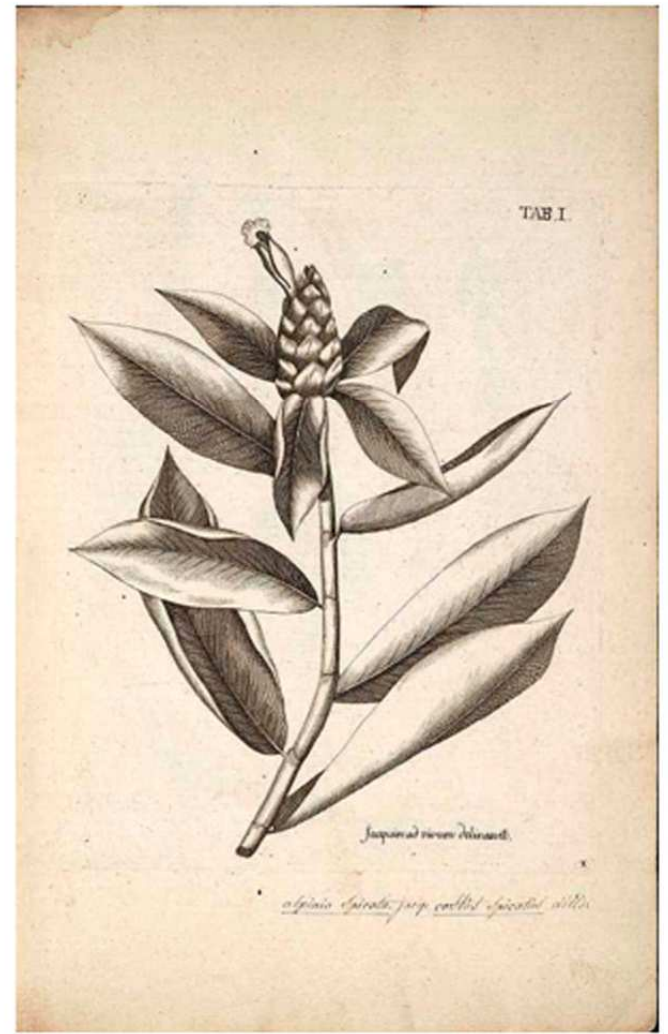

VON JACQUIN, Nikolaus Joseph (1727-1817). Canne de Riviere de Martinica (Caña Cimarrona) o Alpinia Spicata.Selectarum stirpium americanorum historia. Viena, 1763.

\section{EL DIBUJO COMO}

FORMA DE

CONOCIMIENTO EN LA EXPEDICIÓN BOTÁNICA

DEL NUEVO REINO DE GRANADA
Juan Ricardo Rey-Márquez

Doctorando pela Universidad de Buenos Aires. Centro de Investigación en Arte, Materia y Cultura - MATERIA / UNTREF 
Rey-Márquez, Juan Ricardo. El dibujo como forma de conocimiento en la Expedición Botánica del Nuevo Reino de Granada. Domínios da Imagem, Londrina, v. 9, n. 17, p. 101-117, jan./jun. 2015.

ISSN 2237-9126

Recebido em 16/03/2015 e aprovado em 17/06/2015.

Este texto surge de una conferencia inédita dictada en la Biblioteca Luis Ángel Arango de Bogotá.

\section{Resumen}

En el presente artículo se presenta un análisis del uso del dibujo en la Expedición Botánica del Nuevo Reino de Granada. Con este propósito se revisa el concepto de representación vinculado con las ideas sobre ilustración botánica imperantes en el siglo XVIII. Se trata en especial la relación del director de la Expedición, José Celestino Mutis, con el botánico Sueco Carl von Linneo, para establecer la importancia adjudicada al uso de la imagen por Mutis, a diferencia de la prelación adjudicada a la descripción escrita por Linneo.

Palabras clave: Representación. Dibujo Botánico. Descripción escrita.

\section{Abstract}

The present paper aims to analyze the uses of drawing in the Botanical Expedition of the Nuevo Reino de Granada. With this purpose the concept of representation will be revisited in relation to $18^{\text {th }}$ century botanical depiction ideas. We will address specially to the link between José Celestino Mutis-director of the Expedition- and the Swedish botanist Carl von Linneo, in order to establish the importance given by Mutis to drawing in contrast to Linneo's preference to written description.

Keywords: Representation. Botanical drawing. Written description.

La imagen de la colonia sobre la que se tratará a continuación, no es una de las más representativas a los ojos de quienes están acostumbrados a temas religiosos. Sin embargo es una preocupación que se tuvo desde principios de la presencia europea en América y ocupó gran parte de las crónicas de Indias para gloria y orgullo de los monarcas hispánicos. Nos referimos a las representaciones de la naturaleza americana, en especial, las de su flora. Para empezar se propone revisar un concepto fundamental como es el de representación. Este concepto fue una preocupación central en el siglo XVIII, si bien su fundamentación se remonta al siglo anterior. La Escuela de lógica y gramática, o de Port Royal originada en la abadía jansenista de Port-Royal-des- 
Rey-Márquez, Juan Ricardo. El dibujo como forma de conocimiento en la Expedición Botánica del Nuevo Reino de Granada. Domínios da Imagem, Londrina, v. 9, n. 17, p. 101-117, jan./jun. 2015.

ISSN 2237-9126

Champs, cerca de París, fue el lugar en el que Antoine Arnauld (1612-1694) junto a Claude Lancelot (1616-1695) escribieron la Grammaire générale et raisonnée (1660), y en colaboración con el teólogo Pierre Nicole (1625-1695) Logique ou l'art de penser (1662), más conocida como la Lógica de Port Royal. Uno de los aportes trascendentales de Port-Royal es la formulación de la unión entre el lenguaje y la lógica. El axioma central de la lógica de Por Royal es: "todo enunciado posee una dimensión transitiva o transparente por la cual alude a algo fuera de sí mismo, y una dimensión reflexiva $U$ opaca por la que el enunciado habla de sí mismo" (BURUCÚA, 2001, p. 24).

En esta medida, representar implica - literalmente - volver a presentar, tanto como presentar algo en lugar de lo representado. Para entender éste aspecto veamos un ejemplo trabajado por el semiólogo e historiador Lovis Marin en relación con las representaciones del rey; en Le portrait de Roi (1981), Marin explica que un retrato real, es el rey en la medida en que el retrato alude, señala a la persona real pero al mismo tiempo el retrato está en lugar del rey, por lo cual los mismos honores que se le tributarían a la persona regia se le tributan a su representación. En conclusión el retrato del rey no existe sin el monarca, pero al mismo tiempo el monarca comparece ante nosotros, se presenta ante nuestra vista a través de una representación. Esta relación puede verse en el caso de las ceremonias de proclamación real. Para la jura de Fernando VII en 1808, en la población de San Bartolomé de Honda (ubicada en el centro del actual territorio colombiano), la parte central de la ceremonia consistía en la presentación del Rey a sus vasallos a través de su retrato. El Alférez Real, en este caso Joseph Diago, era el funcionario encargado de develar el retrato del monarca y de ésta forma proclamar su presencia simbólica en sus dominios. 
Rey-Márquez, Juan Ricardo. El dibujo como forma de conocimiento en la Expedición Botánica del Nuevo Reino de Granada. Domínios da Imagem, Londrina, v. 9, n. 17, p. 101-117, jan./jun. 2015.

Figura 1

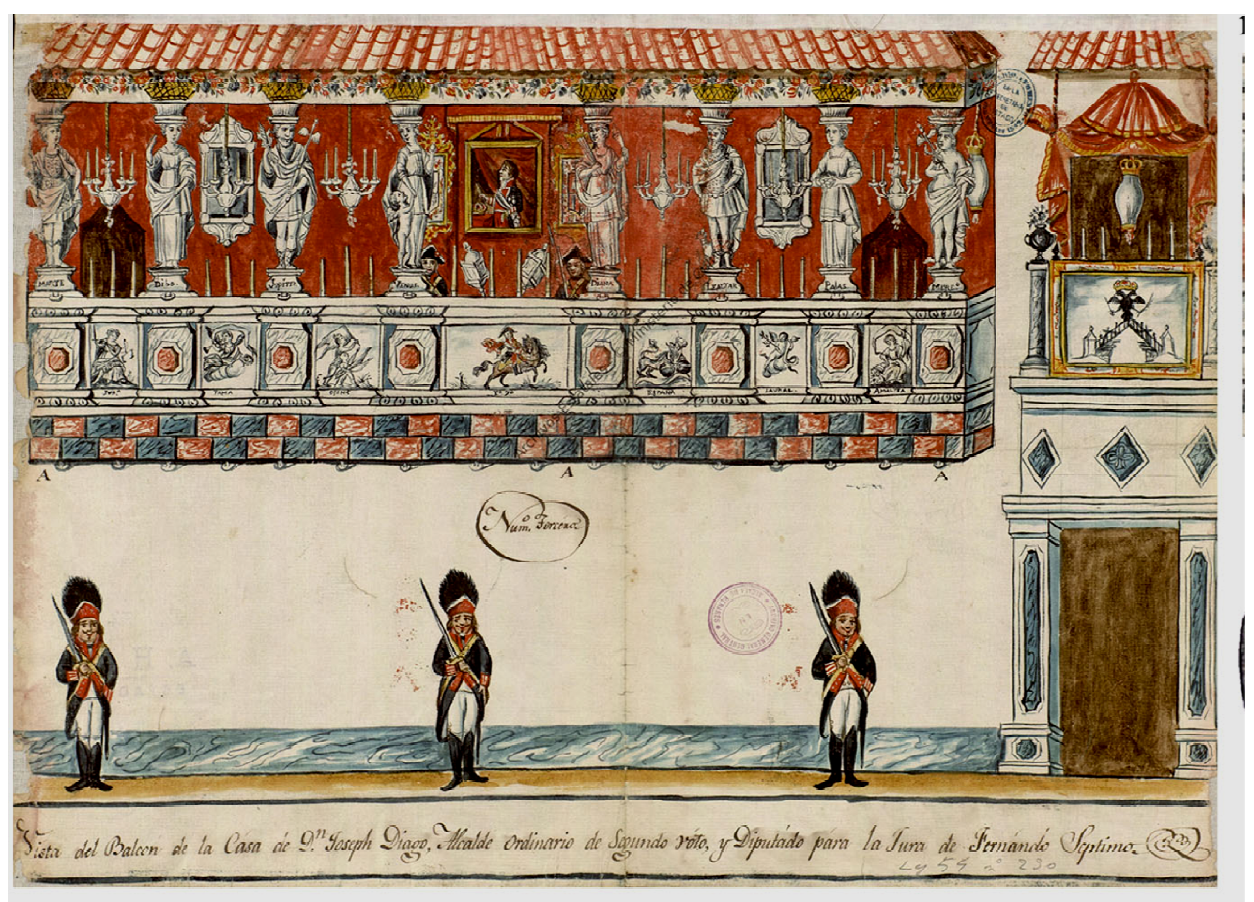

ANÓNIMO. Vista del balcón de la cada de Don Joseph Diago [...] para la Jura de Fernando Séptimo (1808). Acuarela y tinta sobre papel, Archivo general de Indias, Sevilla.

Algo similar sucede con el caso de las representaciones científicas. Para los botánicos de los centros científicos europeos, contar con una representación de las plantas era parte de su estudio pues permitía conocer nuevas especies de lugares remotos y - dependiendo de su fidelidad - conocer aquellos aspectos de la especie viva que se perdían en el herbario de plantas disecadas y prensadas. Ahora esta representación podía ser escrita y/o visual, con la finalidad de clasificar especies nuevas e incluirlas en los diversos catálogos formados en Europa - de manera sistemática - desde el siglo XV. De esta manera gracias a la representación se podía saber si se estaba frente a una 
Rey-Márquez, Juan Ricardo. El dibujo como forma de conocimiento en la Expedición Botánica del Nuevo Reino de Granada. Domínios da Imagem, Londrina, v. 9, n. 17, p. 101-117, jan./jun. 2015.

ISSN 2237-9126

planta conocida por la ciencia, si se trataba de una variedad de una especie ya conocida o si era el caso de una especie nueva. Por otro lado si no existe una representación de la planta, es como si no existiera y en ese aspecto clasificatorio del conocimiento reside el valor de la representación. Gracias a este concepto podemos entender por qué el botánico gaditano José Celestino Mutis, en noviembre de 1777, anotó en su diario la preocupación que le producía: "La falta de una abundante biblioteca (no obstante verse hoy este cerro del sapo [localidad del actual territorio colombiano] favorecido con una pequeña y escogida Biblioteca de más de doscientos libros, escogidos y costosísimos)" (HERNÁNDEZ DE ALBA, 1983, p. 209).

Mutis, nacido en Cádiz y formado como médico romancista y cirujanol en su ciudad natal, había arribado a Cartagena de Indias en el Nuevo Reino de Granada - en el caribe colombiano - en calidad de médico del Virrey Pedro Messia de la Cerda. Mutis abrigaba el deseo de formar una expedición botánica en la América equinoccial, lo cual pudo lograr dos décadas después de su arribo. Para noviembre de 1777 - fecha de la anotación sobre su biblioteca - Mutis se encontraba en el Real de Minas del Sapo en el interior del virreinato, al frente de un proyecto minero con el que pretendía financiar sus expediciones. Al día siguiente de la anotación citada, Mutis se decidió a recorrer la región circundante a su mina en compañía de un lugareño, con ayuda de la edición española de la Historia natural de Plinio (Madrid, 1624) realizada por Gerónimo de la Huerta para "...recoger los jugos, gomas, resinas y bálsamos de todos los árboles de aquí" (HERNÁNDEZ DE ALBA, 1983, p. 212).

\footnotetext{
1 Ambas actividades se encontraban separadas desde la antigüedad. El médico romancista era aquel que conocía de farmacopea - especialmente botánica - mientras que el cirujano era el encargado de realizar intervenciones quirúrgicas. La primera ocupación se tenía por noble, mientras que la segunda había sido tenida por baja, a pesar de los avances logrados en los siglos XV y XVI en anatomía, gracias a la disección de cadáveres. Mutis deseaba - como siglos atrás lo hiciera Andrea Vesalio - unificar ambas facetas de la medicina.
} 
Rey-Márquez, Juan Ricardo. El dibujo como forma de conocimiento en la Expedición Botánica del Nuevo Reino de Granada. Domínios da Imagem, Londrina, v. 9, n. 17, p. 101-117, jan./jun. 2015.

ISSN 2237-9126

Plinio era una autoridad en historia natural nada desdeñable, a pesar de tratarse de un autor clásico en cuya obra no aparece el estudio de las especies americanas. No obstante era el autor por el que se había guiado Francisco Hernández (1517-1587), "Protomédico e historiador de su majestad Don Felipe ॥ en todas las Indias Occidentales, Islas y Tierra Firme del Mar Océano", nombrado como tal en 1570. Hernández, una fuente de inspiración para Mutis, quizá fuera una de las más importantes figuras de la Historia Natural hispánica. Durante su estadía en Nueva España, el médico toledano había terminado una traducción de Plinio que iniciara en España hacia 1567 (ÁLVAREZ PELÁEZ, 1993, p. 106-107). El gaditano sabía del trabajo de su compatriota y deseaba culminarlo pues sabía que se encontraba parcialmente inédito. Pero esa es otra historia.

De regreso a Mutis, aunque tuviera de su parte a Plinio necesitaba textos específicos sobre el Nuevo Reino de Granada, es decir "...consultar a los viajeros y otros autores, que pueden haber visto algunas de estas producciones de la naturaleza en estos fertilísimos países de la América". Esa misión la cumplió con creces el trabajo del misionero y explorador jesuita José Gumilla (16861750). Mutis había reconocido árboles de caucho en lbagué, lo cual lo animó a confirmar las referencias sobre árboles resinosos. Como diría Lovis Marin, Mutis necesitaba estar en capacidad de ver (MARIN, 1993, p. 18) y para ello necesitaba de representaciones tanto visuales como escritas. Pero la edición española de Plinio no cuenta con imágenes botánicas. De hecho en las ediciones de Plinio y Gumilla que consultó Mutis, de las que sabemos gracias al inventario de su biblioteca ${ }^{2}$, las plantas aparecen solamente en representaciones escritas.

\footnotetext{
2 Una transcripción del inventario de la "librería botánica" se encuentra en la colección de raros y manuscritos de la Biblioteca Luis Ángel Arango de Bogotá. El documento corresponde al momento de cierre de la Expedicion Botánica en el período republicano, en 1816, en medio de la Guerra de Independencia. La transcripción fue realizada por el historiador colombiano Guillermo Hernández de Alba, quien dedicó gran parte de su vida a la investigación de Mutis y
} 
Rey-Márquez, Juan Ricardo. El dibujo como forma de conocimiento en la Expedición Botánica del Nuevo Reino de Granada. Domínios da Imagem, Londrina, v. 9, n. 17, p. 101-117, jan./jun. 2015.

ISSN 2237-9126

Figura 2

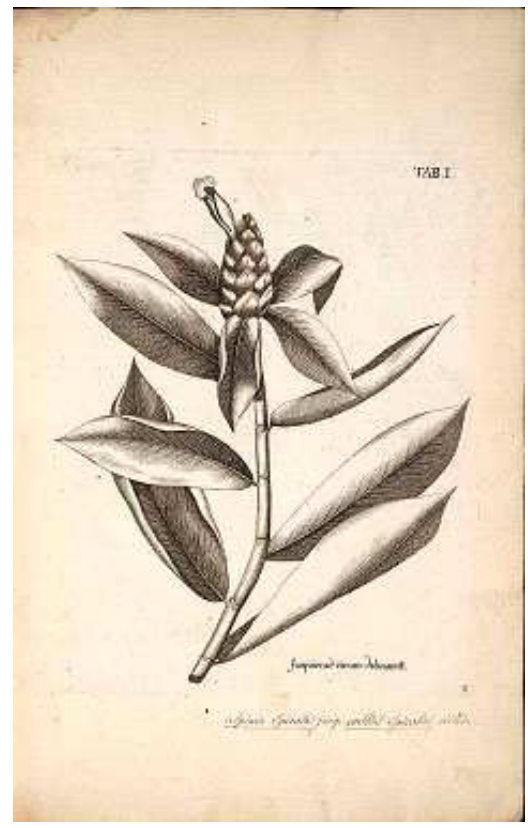

VON JACQUIN, Nikolaus Joseph (1727-1817). Canne de Riviere de Martinica (Caña Cimarrona) o Alpinia Spicata. Selectarum stirpium americanorum historia Viena, 1763.

Este es un detalle crucial. Aunque se acostumbraba la realización de imágenes botánicas, resultaba sumamente costoso -además de poco práctico desde un punto de vista editorial- hacer ediciones completamente ilustradas. Las imágenes por lo general se tenían que hacer en pliego aparte e incluirse bien fuera al principio de la obra o al final, aunque en algunos casos se intercalaban con el texto. Mutis tuvo acceso a una amplia colección de libros botánicos en los que las imágenes jugaban un papel clave. Es el caso de Selectarum stirpium americanorum historia, publicado en Viena en 1763 por Nikolaus Joseph von Jacquin (1727-1817). Jacquin estuvo en el Caribe entre 1757-1760 financiado por la Corte Imperial Austriaca, recolectando materiales.

su obra. Hernández de Alba, Guillermo, (transcripción) Inventario de la librería de la casa que fue la botánica al cargo del doctor Mutis. Biblioteca Luis Ángel Arango, Libros Raros y Manuscritos, Registro MSS2670. 
Rey-Márquez, Juan Ricardo. El dibujo como forma de conocimiento en la Expedición Botánica del Nuevo Reino de Granada. Domínios da Imagem, Londrina, v. 9, n. 17, p. 101-117, jan./jun. 2015.

ISSN 2237-9126

La primera lustración de una especie americana en su obra, corresponde a la Canne de Riviere de Martinica (Caña Cimarrona) o Alpinia Spicata. Como vemos esta representación cumple con la teoría de representación de Port Royal: en primer lugar está la dimensión reflexiva que hace comparecer a la caña cimarrona a nuestra presencia, está en lugar de la caña natural remplazándola; de otra parte la dimensión transitiva u opaca en este caso tiene un sentido político, pues un botánico francés al servicio de la corte austriaca muestra cómo pudo hacer presencia en América para representar especies en territorio borbón antes que botánicos españoles. En el margen inferior tiene una inscripción que dice "Jacquin ad vivum delineavit" que podría traducirse como "dibujada por Jacquin del natural" (Jacquin, 1765: s.p.).

III

Figura 3

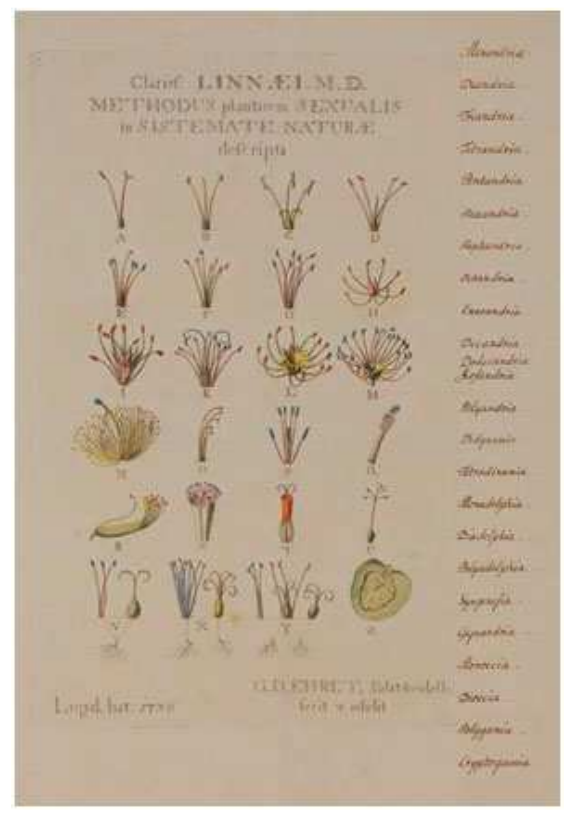

EHRET, Georg Dionysius (1708-1770). Linnaei methodus plantarum sexuales. 1736. 
Rey-Márquez, Juan Ricardo. El dibujo como forma de conocimiento en la Expedición Botánica del Nuevo Reino de Granada. Domínios da Imagem, Londrina, v. 9, n. 17, p. 101-117, jan./jun. 2015.

ISSN 2237-9126

En botánica las representaciones escritas tenían prelación. Denominadas técnicamente taxón del latín Taxatio, que significa apreciar, valorar, estas representaciones contenían las principales características de los órganos sexuales de la planta. Esta forma descriptiva seguía la revolucionaria propuesta de clasificación del botánico sueco Carl von Linneo (1707-1778), que al principio le valió la censura papal de Clemente XIII quien ordenó en 1757 quemar sus obras por la mera sugerencia de contacto sexual de las plantas. La decisión sería reconsiderada en 1774. Esta propuesta revolucionaria fue plasmada en la estampa Linnaei methodus plantarum sexuales (1736) del dibujante y grabador botánico de origen alemán Georg Dionysius Ehret (17081770), que trabajó con el botánico sueco en el desarrollo de una síntesis de su propuesta de clasificación sexual. Este grabado aparece citado por múltiples autores para demostrar el gusto por las imágenes de Linneo.

Pero en realidad el sabio sueco tenía una mirada particular al respecto. La relación de Linneo con la imagen era contradictoria (AMAYA, 2005), aunque algunos autores asumen que tomó partido en favor de su uso sin mayores reparos (BLEICHMAR, 2012) e incluso se afirma que describió un tipo particular de "analytic gaze" (KROMM, 2010). Entre tanto otros matizan su uso aduciendo su pertenencia a un proceso más amplio que le daba mayor preponderancia a Ios herbarios (NIETO OLARTE, 2000, p. 67-71; 125-128). Incluso se ha presentado a Linneo como favorable al dibujo, a pesar de aspectos de su biografía que apuntan en otra dirección como su notable desatención a las representaciones visuales en uso durante su etapa de formación en Holanda, cuando publicó su Philosophia Botánica (1751) (GONZÁLEZ BUENO, 2000). En la traducción castellana del siglo XVIII de la Philosophia de Linneo se lee: 
Rey-Márquez, Juan Ricardo. El dibujo como forma de conocimiento en la Expedición Botánica del Nuevo Reino de Granada. Domínios da Imagem, Londrina, v. 9, n. 17, p. 101-117, jan./jun. 2015.

ISSN 2237-9126

Como no siempre se pueden poner à la vista las figuras, ni tampoco demostrar por ellas las más menudas partes de la fructificación de algunas plantas, son necesarias las descripciones, y aún éstas hacen siempre más al caso que las figuras (PALAU I VERDERA, 1778, p.240)

Linneo defendía su método de clasificación sexual de las plantas denominado por él nomine genérico. Como indica el nombre se trataba de una representación escrita, es decir, de darle un nombre a las especies botánicas seguido de una descripción - un taxón - pues para Linneo la descripción escrita era mejor que la imagen. Tanta fe le tenía a su método el sabio sueco que, haciendo una alusión, pensaba haber encontrado en él el hilo de Ariadna que sacaría a los botánicos del laberinto de la naturaleza:

[...] si a un botánico sin sistema [linneano], se le presenta alguna planta no conocida, por más que acuda a las descripciones, a las figuras y a todos los índices, no acertará con su nombre ni por casualidad; pero el Botánico sistemático al instante determinará el género de la planta [...] (PALAU I VERDERA, 1778, p. 83)

A diferencia de Linneo, Mutis tenía mayor fe en la capacidad de las imágenes para conocer la naturaleza, incluso desde antes de dirigir la Expedición. El 20 de mayo de 1774, Linneo le comunicó a Mutis que su muestra de Quina de Bogotá o Cinchona Bogotensis para él era "Carica papaya". Mutis le responde en su carta de febrero de 1777 que la Carica papaya "...en mi catálogo es Cinchona bogotensis, igual a la del Perú..." y más adelante dice "hice un muy bello dibujo" (AMAYA, 2008, p. 48) con lo cual parece reforzar la seguridad de sus observaciones. Entonces, muy alejado de la mirada de Linneo, para el gaditano el dibujo resulta una forma de observación segura. 
Rey-Márquez, Juan Ricardo. El dibujo como forma de conocimiento en la Expedición Botánica del Nuevo Reino de Granada. Domínios da Imagem, Londrina, v. 9, n. 17, p. 101-117, jan./jun. 2015.

ISSN 2237-9126

\section{IV}

Mutis fue corresponsal botánico de Linneo, hasta la muerte de este último. Cuando el botánico gaditano al fin obtuvo la autorización para adelantar la Expedición Botánica de Nuevo Reino de Granada, en 1783, como Botánico del Rey decidió darle un lugar preponderante al dibujo. Veamos como ejemplo un caso particular. El 7 de enero de 1784, el botánico Eloy Valenzuela apunta en su diario que estaba consultando el Supplementum plantarum de Linneo para buscar un Cacao de Monte, del género Theobroma. Valenzuela, colaborador de Mutis, quería determinar si Linneo había descrito ya una planta que coincidiera con la especie hallada por él en las inmediaciones de Mariquita, población de la zona central neogranadina (VALENZUELA, [1783-1784] 1983, p. 314). Desde luego Valenzuela estaba buscando en un libro compuesto por taxones en latín, a pesar de lo cual le parecía que la especie hallada por él superaba a la Theobroma augusta descrita por Linneo y declara:

El color [de la flor] es también purpúreo triste, y ésta que le pareció a Linné Speciocisima Planta Spectabilissima Fructificatione [Hermosísima planta, notabilísima fructificación] es muy inferior a la que yo he logrado ver y examinar. Qué dijera él con el nectario tan arrogante y hermoso de la mía (VALENZUELA, [1783-1784] 1983, p. 314).

Cuando Valenzuela dice "que yo he logrado ver y examinar" parece denotar que le decepciona la descripción escrita. Leer un taxón implica el ejercicio de imaginar una planta a partir de la enumeración de pétalos, estambres, pistilos, forma de la hoja, etc. Por ello se pregunta Valenzuela lo que diría en su descripción Linneo de un "nectario tan arrogante" como el que él había 
Rey-Márquez, Juan Ricardo. El dibujo como forma de conocimiento en la Expedición Botánica del Nuevo Reino de Granada. Domínios da Imagem, Londrina, v. 9, n. 17, p. 101-117, jan./jun. 2015.

ISSN 2237-9126

presenciado 3 . En realidad la imagen era más elocuente que la descripción y sobre todo más útil para fines de exploración. Lo cual no implica que haya una supremacía de la representación visual sobre la textual, sino que ambas tienen ámbitos diferentes irreductibles entre sí.

En la dimensión transitiva u opaca de esta representación, aparece un aspecto interesante relacionado con el tiempo. Francisco Javier Matis, probable autor del dibujo, recién incorporado a la Expedición (18 de diciembre de 1783) empleó los días 9 y 10 de marzo para dibujar la Theobroma que apenas se había descrito completamente el día 8 de marzo (VALENZUELA, [1783-1784] 1983, p. 369-371). Pero el dibujo no se hizo en dos días, pues habían transcurrido dos meses desde el hallazgo de la planta - cuando Valenzuela mandó a hacer la flor - y el dibujo del fruto sólo se pudo hacer después de hallar uno en buen estado, justo el día anterior de la descripción (VALENZUELA, [1783-1784] 1983, p. 369). Sin embargo a pesar del tiempo de trabajo invertido por los botánicos, los herbolarios y el dibujante Matis, Valenzuela escribió sobre la "graciosa theobroma [...] como era primer ensayo, y faltaron los ingredientes para el morado de ella, salió este poco natural, y el retrato con mucha pérdida en su hermosura..." (VALENZUELA, [1783-1784] 1983, p. 371). No tenemos seguridad de que el dibujo decepcionante fuera el actualmente conservado en la colección del Jardín Botánico de Madrid4, pues el equipo de Mutis solía realizar varias versiones de sus láminas hasta obtener la representación más adecuada a sus propósitos. Pero lo que tenemos en claro es que a Valenzuela y a Mutis les parecía insuficiente con el taxón.

\footnotetext{
${ }^{3}$ El nectario es una especie de pétalo compuesto, en forma de labio, presente en algunas flores.

${ }^{4}$ Se sugiere observar las imágenes producidas por el equipo mutisiano en la página del Real Jardín Botánico de Madrid, que presenta una digitalización de gran calidad. El enlace en el que se encuentra la página es Mutis (s.d.)
} 
Rey-Márquez, Juan Ricardo. El dibujo como forma de conocimiento en la Expedición Botánica del Nuevo Reino de Granada. Domínios da Imagem, Londrina, v. 9, n. 17, p. 101-117, jan./jun. 2015.

ISSN 2237-9126

Hay un ejemplo más elocuente relacionado con una batatilla de fucha. Mutis, en una carta a su colaborador Eloy Valenzuela, fechada en Mariquita, el 9 de junio de 1784 dice:

Está ya dibujada mi Condaminia Ornithogaloides. Con este motivo he sospechado, si aquella batatilla que vimos en Fucha podrá militar bajo de éste singularísimo género. Raras eran las narices del buen viejo Linneo! nada se atrevió a pronunciar en la lámina del Catesby, cuyo Ornythogalum es tan parecido (como hicimos memoria al verla) a esa plantica (AEl: 203-204).

Mutis se refiere a Mark Catesby (1682-1749), explorador de Carolina, Florida y las Bahamas, había publicado su Historia Natural en tres volúmenes aparecidos el primero en 1731, el segundo en 1743 y el apéndice en 1743 (MEYERS, 1997, p.18). La obra del inglés tenía imágenes que podían estar iluminadas, es decir con color, tomado de las ilustraciones originales, según lo solicitaran expresamente los compradores por un precio de dos guineas (en blanco y negro el valor se reducía a la mitad) (MEYERS, 1997, p.17). La imagen que recuerda Mutis es la Ornithogalum.

Cuando vieron la Batatilla, Mutis y Valenzuela se encontraban de camino a Mariquita en lo que sería actualmente el barrio del Tunal, entonces en las afueras de Santafé, a orillas del río Fucha. Ante la duda Mutis escribe: "De mi dibujo no puedo acordarme, y no es para todos los días revolverlos con pérdida de tiempo" a continuación describe la planta y pide a Valenzuela que la coteje con el espécimen que tienen, para determinar si es Condaminia o una planta diversa (HERNÁNDEZ DE ALBA, 1983, p. 203-204). Valenzuela, formado en botánica con Mutis, hizo por su parte una descripción de la planta en su propio diario. Gracias a estos detalles descriptivos, se puede pensar en dos láminas posibles el Curculigo (Sign. DIV. III A-278 RJB, Madrid) y la otra el Anthericum (Sign. DIV. III A-242 RJB, Madrid). Como en el ejemplo del Cacao de Monte entre 
Rey-Márquez, Juan Ricardo. El dibujo como forma de conocimiento en la Expedición Botánica del Nuevo Reino de Granada. Domínios da Imagem, Londrina, v. 9, n. 17, p. 101-117, jan./jun. 2015.

ISSN 2237-9126

el momento de observación de la batatilla en el viaje a Mariquita, el 30 de abril de 1783, y el recuerdo de la misma disparada por la lámina de Catesby, el 9 de junio de 1784, transcurrió poco más de un año y dos meses. Al respecto Mutis apunta en su diario:

Entre las plantas de la mañana vino también la Batatilla con la flor amarilla terminal hexandra, monoginia hexapétala frecuentísima en las sabanas de Santafé [hoy Bogotá], que tienen muchísima semejanza con el Ornithogalum luteum [...] de Catesby. Lam. 33, tom., 1 que Linne lo deja sin nombre. Yo advertí en Santafé al reconocer estas láminas que podía ser una misma planta, aunque la de Catesby, tal vez por descuido o variedad, tiene cinco pétalos y cinco estambres. Me avanzaba en mi conjetura al ver pintada en la misma lámina la Alanda Magna, que es justamente el Bícharo de las sabanas de Santafé, aunque con alguna variedad. Al reconocer mi compañero estas láminas el domingo pasado dio en el mismo pensamiento. Falta, pues, comparar la de aquí con la de Santafé que tengo dibujada (HERNÁNDEZ DE ALBA, 1983, p.149).

Mutis advierte entonces un error en el dibujo de Catesby jle falta un pétalo a la planta! Pero el resto de características coincidían con la especie por él conocida. Mutis tenía razón. El pétalo faltante se perdió en la edición del libro, como se comprueba al examinar los originales del explorador inglés en la colección Real de Windsor ${ }^{5}$. Es interesante que a través de un dibujo de la flora de Carolina, en Norte América, pudiera Mutis reconocer una planta. Adicionalmente el detalle de la observación del pájaro nos hace caer en cuenta que el proyecto mutisiano era mucho más amplio de lo que se conserva. Hay muchos dibujos perdidos entre los que se encuentran sus obras de pájaros, para no mencionar el caso de las obras de caballete como las pinturas de castas.

5 La imagen se encuentra en Catesby (s.d.). 
Rey-Márquez, Juan Ricardo. El dibujo como forma de conocimiento en la Expedición Botánica del Nuevo Reino de Granada. Domínios da Imagem, Londrina, v. 9, n. 17, p. 101-117, jan./jun. 2015.

ISSN 2237-9126

\section{V}

Para entender la dimensión que alcanzó la representación en el proyecto científico mutisiano, hay que considerar los tipos de publicación que tenía en mente en los cuales las representaciones visuales tenían mucha importancia. Meses antes del cotejo del Ornithogalo, el 31 de marzo de 1784, Mutis le dirige una carta a don Casimiro Gómez Ortega, director del Real Jardín Botánico. Allí le dice que tiene en su mente tres tipos de publicación para su obra botánica: Compendios anvales con "...todos los descubrimientos con el fin de asegurar la data..." es decir una publicación en la que las representaciones escritas - los taxones - priman sobre las representaciones visuales pues tendrían "...la descripción del género, con un catálogo seguido de todas sus especies..." diferenciando entre géneros conocidos y géneros nuevos; sobre las ilustraciones, en tamaño folio, dice Mutis: "...Se acompañarán solamente la flor, la fruta y semilla de alguna especie" nótese el sistema sexual linneano abreviado por lo que comenta "Con láminas tan sencillas se abrevia la edición...". La Grande Flora, segundo tipo de publicación, tendría "todas las especies" de la Flora Americana "en castellano, con su especial descripción y erudición" pero con prelación de las representaciones visuales pues cada planta tendría "una suntuosa lámina en el gusto de nuestro siglo". La publicación restante sería el primer volumen o pródromo de la Grande Flora: la Historia Natural de Quina (HERNÁNDEZ DE ALBA, 1983, p.180-181)6.

Mutis le explica a Ortega la importancia del dibujo en la clasificación: "las especies no bien determinadas anteriormente por los viajeros de América, en defecto de los principios más ciertos que hoy tenemos o aquellas que carecieren de un buen dibujo, serán igualmente llamadas a nuevo examen e

\footnotetext{
- La palabra latina Pródromo, que traduce "precursor" es el nombre dado a la primera
} publicación en las publicaciones botánicas. 
Rey-Márquez, Juan Ricardo. El dibujo como forma de conocimiento en la Expedición Botánica del Nuevo Reino de Granada. Domínios da Imagem, Londrina, v. 9, n. 17, p. 101-117, jan./jun. 2015.

ISSN 2237-9126

ilustradas con su correspondiente lámina" (HERNÁNDEZ DE ALBA, 1983, p.181). Esta frase parece aludir a Catesby. Mutis y Valenzuela se preocupan por la batatilla de Fucha, para ver si era planta ya descrita o no. Recordemos que en su carta a Valenzuela, Mutis creía haber encontrado una planta no descrita por Linneo, pues Catesby la dibujó en un viaje anterior a las publicaciones del sabio sueco. Tanta fue la alegría que escribió "Raras eran las narices del buen viejo Linneo! nada se atrevió a pronunciar en la lámina del Catesby" (HERNÁNDEZ DE ALBA, 1983, p. 204).

En los casos citados puede verse como Mutis tuvo una mirada particular sobre el uso de las imágenes. Tanto en la clasificación del Cacao de Monte como en el de la Batatilla se hace patente una complementariedad entre las representaciones visuales y escritas. Para recordar las especies vistas, Mutis acude a los trabajos dibujados por sus colaboradores como auxiliares de la memoria. El lugar de lo escrito parece dejarse para la fijación del conocimiento. De la misma forma que en la jura real, las representaciones visuales funcionan no solo como sustitutas de lo representado al hacer comparecer las plantas ante los ojos de los botánicos; adicionalmente dibujar implicaba conocer, aunque la tarea de representar todas las especies estudiadas demandara un esfuerzo gigantesco. El tiempo empleado en ubicar las plantas y representarlas - en dibujo y por escrito - implicaba una labor dilatada de reflexión y estudio. Este tipo de dibujo reúne entonces varias facultades del intelecto: conocer y recordar lo representado en su dimensión transitiva o transparente, pero también idealizar, lo cual implica una dimensión reflexiva u opaca de conocimientos condensados. Esta opacidad del dibujo botánico, se oculta tras la condensación de tiempo y conocimiento, experiencia y diferentes disciplinas en un espectro que va del arte a la ciencia para formar un tipo de imagen visual densa, rica en conocimiento y saberes europeos y americanos. 
Rey-Márquez, Juan Ricardo. El dibujo como forma de conocimiento en la Expedición Botánica del Nuevo Reino de Granada. Domínios da Imagem, Londrina, v. 9, n. 17, p. 101-117, jan./jun. 2015.

ISSN 2237-9126

\section{Referencias}

ÁlVAREZ PELÁEZ, Raquel. La conquista de la naturaleza americana. Madrid: Consejo Superior de Investigaciones Científicas - CSIC, 1993.

AMAYA, José Antonio. Ciencia y arte en el Nuevo Reino de Granada. In: Mutis al natural. Ciencia y arte en el Nuevo Reino de Granada. Bogotá: Museo Nacional de Colombia, 2008.

AMAYA, José Antonio. Mutis, apóstol de Linneo. Historia de la botánica en el virreinato de la Nueva Granada, 1760-1783. Tomo I. Bogotá: Instituto Colombiano de Antropologia e Historia, 2005.

BLEICHMAR, Daniela. Visible Empire. Botanical Expeditions \& Visual Culture in the Hispanic Enlightenment. Chicago, The University of Chicago Press, 2012.

BURUCÚA, José Emilio. Corderos y elefantes. La sacralidad y la risa en la modernidad clásica -siglos XV a XVII. Buenos Aires, Universidad de Buenos Aires Miño y Dávila, 2001.

CATESBY, Mark. The Natural History of Carolina, Florida, and the Bahama Islands. Vol.1. Disponible en: Digital Collections of the University of North Carolina University http://dc.lib.unc.edu/cdm/compoundobject/collection/dmisc/id/1658/rec/l. Accedido el: 23 jul. 2015.

GONZÁLEZ BUENO, Antonio. El príncipe de los botánicos Linneo. Madrid: Nivola Libros y Ediciones, 2001.

HERNÁNDEZ DE ALBA, Guillermo, Diario de observaciones de José Celestino Mutis (1760-1790). Tomo I. Bogotá: Instituto Colombiano de Cultura Hispánica/Ediciones del segundo centenario de la Real Expedición Botánica. 1983.

HERNÁNDEZ DE ALBA, Guillermo. Archivo epistolar del sabio naturalista don José Celestino Mutis. 2 Tomos (segunda edición). Bogotá, Instituto Colombiano de Cultura Hispánica/Ediciones del segundo centenario de la Real Expedición Botánica. 1983.

KROMM, Jane, To collect is to quantify and describe: visual practices in the development of modern science. In: BAKEWELL, Benforado; KROMM, Susan; 
Rey-Márquez, Juan Ricardo. El dibujo como forma de conocimiento en la Expedición Botánica del Nuevo Reino de Granada. Domínios da Imagem, Londrina, v. 9, n. 17, p. 101-117, jan./jun. 2015.

ISSN 2237-9126

KROMM, Jane. (Edits.) A history of visual culture. Western civilization from the 18th to the 21st century. Nueva York, Berg, 2010.

MARIN, Louis. Des pouvoirs de l'image. Gloses. París, Éditions du Sevil, 1993.

MEYERS, Amy R. W. The perfecting of natural history: Mark Catesby's Drawings of American Flora and Fauna in the Royal Library, Windsor Castle. In: Mark Catesby's Natural History of America, Catálogo de la exposición, Londres, Merrel Holberton/The Houston Museum of Art, 1997.

MUTIS. Disponible en: http://www.rjb.csic.es/icones/mutis/paginas/index.php. Accedido el: 23 jul. 2015.

NIETO OLARTE, Mauricio. Remedios para el imperio. Historia natural de la apropiación del Nuevo Mundo. Bogota, Instituto Colombiano de Antropología e Historia, 67-71, 125-128, 2000.

PALAU I VERDERA, Antoni. Explicación de la filosofía y fundamentos botánicos de Linneo. Madrid: Antonio de Sancha. 1778.

VALENZUELA, Eloy; ARBELÁEZ, Enrique Pérez (Edit.). Primer diario de la Real Expedición Botánica del Nuevo Reino de Granada. Bogotá: Instituto Colombiano de Cultura Hispánica., [1783-1784], 1983. 